\title{
Theranostic nanoplatforms for treatment and diagnosis of rectal and colon cancer: a brief review
}

\author{
Yaser Hadi Gholami ${ }^{1,3,4}$, Alexander Engel ${ }^{2,3,4}$ \\ 'School of Physics, University of Sydney, Sydney 2006, Australia. \\ ${ }^{2}$ University of Sydney, Sydney 2006, Australia. \\ ${ }^{3}$ Bill Walsh Translational Research Laboratories, Kolling Institute of Medical Research, St Leonards 2065, Australia. \\ ${ }^{4}$ Sydney Vital Translational Cancer Research Centre, St Leonards 2065, Australia.
}

Correspondence to: Dr. Alexander Engel, University of Sydney, Sydney 2006, Australia. E-mail: alexander.engel@sydney.edu.au

How to cite this article: Gholami YH, Engel A. Theranostic nanoplatforms for treatment and diagnosis of rectal and colon cancer: a brief review. Mini-invasive Surg 2018;2:44. http://dx.doi.org/10.20517/2574-1225.2018.44

Received: 2 Jun 2018 First Decision: 13 Nov 2018 Revised: 7 Dec 2018 Accepted: 11 Dec 2018 Published: 26 Dec 2018

Science Editor: Gordon N. Buchanan Copy Editor: Cui Yu Production Editor: Huan-Liang Wu

\begin{abstract}
Colorectal cancer (CRC) is a common health problem due to its high prevalence and high mortality rate. Adjuvant and neo-adjuvant strategies, chemotherapy and radiotherapy alone or in combination, have substantially improved survival and local recurrence rates. Their effectiveness remains limited due to the intrinsic build-up of resistance of cancer cells to chemotherapy drugs, dose-limiting toxicities and other major side effects. New strategies to overcome these issues are being developed, one of which is cancer nanomedicine, a rapidly developing interdisciplinary research field. The last few decades have seen a rapid growth of interest in utilising nanoparticles and nanotechnology in cancer medicine. This is mainly due to the suitable physical and chemical properties of nanoparticles for in vivo applications. Cancer nanomedicine for targeted drug delivery and imaging has been widely investigated preclinically and clinically. Nanomedicine has been considered as a novel solution to enhance CRC diagnosis and treatment, both separately and in combination using theranostic techniques. This review highlights the research, opportunities, and challenges for the development of nanoplatforms for diagnosing and treating CRC.
\end{abstract}

Keywords: Nanomedicine, colorectal cancer, nanoparticles

\section{INTRODUCTION}

Colorectal cancer $(\mathrm{CRC})$ is the third most diagnosed cancer in the world ${ }^{[1-3]}$. In stage III rectal cancer surgical resection followed by adjuvant chemotherapy, and of late neo-adjuvant chemo-radiotherapy in locally advanced disease, survival rates up to $58 \%$ at 5 years ${ }^{[3-6]}$ have been reported. Recurrence, local

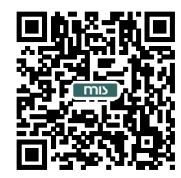


and/or distant, may occur in up to approximately $50 \%$ of patients, but 5 -year survival if curative reresection or Ro metastasectomy is achieved, may still be from $22 \%-49 \%{ }^{[7,8]}$. In primary CRC survival is very much stage dependent and varies from 90\% 5-year survival rate in stage I rectal cancer to less than $10 \%$ of people diagnosed with distant metastatic cancer ${ }^{[6,9]}$. Lymph-node (LN) metastases are the most powerful predictor of survival and need for adjuvant treatment in all solid cancer and almost always follow a well-defined tumour-draining lymph node basin $^{[10]}$. Due to their small size and poor vascularisation, LN metastases are difficult to detect with certainty using conventional imaging modalities. Given that chemotherapy and radiation in the (neo-) adjuvant setting have their specific adverse effects and limited efficacy profile, it is imperative to increase the diagnostic accuracy of LN metastases in the pre-operative setting $^{[11]}$. Nanomedicine may offer an alternative and potentially may be more effective in diagnostics. In combination with therapeutics, it may offer a less toxic theranostic pathway ${ }^{[12-20]}$. The present paper highlights the current understanding of nanomedicine and its role in the management of CRC, and rectal cancer in particular. Nanomedicine is in its adolescence and is slowly transitioning from cell and animal studies towards human trials. To develop appropriate first-in-human trials it is important for clinicians to understand the variety of nano-platforms and particles currently available along with their specific features.

\section{NANOMEDICINE}

The ability to explore the structure and characteristics of materials at the nanoscale has made a great change in many fields of science such as medicine. In the comparison of nanoparticles to their bulk systems, the main properties of nanoparticles that make them fundamentally different in their behaviour are surface-related characteristics and quantum characteristics ${ }^{[2-25]}$. Efficient drug and medical radioisotopes loading (due to the highly reactive surfaces of nanoparticles) in combination with unique physical (e.g., magnetic) properties of nanoparticles have led to rapidly growing interest in nanoparticles for medical applications such as drug delivery and imaging ${ }^{[26-33]}$. Particles or molecules with 10-100 atoms (at least in one dimension) are normally regarded as nanoparticles ${ }^{[34-37]}$ [Figure 1]. Generally, nanoparticles are sized between 1-100 nanometers. Nanoparticles compared to their bulk system (e.g., microparticles) have high surface area-to-volume ratio. Therefore in a nanoparticle, the number of atoms at the surface is greater than those within their internal core and consequently they have a high number of interaction sites available at the surface which makes them chemically more reactive ${ }^{[38]}$. Moreover, at nano-scale where the size of particles (e.g., nanocrystal) is comparable to the de Broglie wavelength of an electron, the change in electronic energy levels become discretely discrete, a condition known as the quantum confinement of the electron wave function ${ }^{[39]}$. This effect is responsible for some of the unique behaviour (e.g., optical) of nanoparticles such as quantum dots. These unique properties (e.g., optical, magnetic, active surface) give nanoparticles the potential to be used as a diagnostic agent or carrier for delivering therapy and thus to be an ideal platform for developing theranostic nano-agents in medicine.

\section{NANO-PLATFORMS FOR DRUG DELIVERY}

Tumour tissues of different cancer types such as colon, breast, prostate and lung cancer are permeable to nano-molecules and nanoparticles ${ }^{[40-42]}$. This is due to their distinctive structural characteristics such as the hyper-permeable vasculature and impaired lymphatic drainage ${ }^{[40,43,44]}$. Nanoparticle and nanomolecule drug delivery mechanisms can be classified into active and passive targeting. Active targeting highly depends on the interaction between the target cell receptors and nanoparticles whereas passive targeting relies on a number of factors such as longer biological half-life, long-circulating time at tumour locations and the flow rate of nanoparticles to the impaired lymphatic system ${ }^{[45-49]}$. Moreover, the enhanced permeability and retention effects and nanoparticle clearance by the mononuclear phagocyte system play an important role in determining the effectiveness of the nano-platform drug delivery system ${ }^{[4,50]}$. The reticuloendothelial system (RES) effect is one of the most common problems among all different 
Table 1. Current nanoplatforms under preclinical development for colorectal cancer ${ }^{[58-62]}$

\begin{tabular}{|c|c|c|}
\hline Formulation & Ligand & Target \\
\hline Nanosized particle & Antibody & Carcinoembryonic antigen (CEA) \\
\hline $\begin{array}{l}\text { Dextran and PEG-coated superparamagnetic } \\
\text { iron oxide nanoparticles }\end{array}$ & Single-chain Fv antibody fragment (scFv) & CEA \\
\hline Gold and iron oxide hybrid nanoparticle & scFv & A33 antigen \\
\hline Polymer capsules & Humanized A33 monoclonal & Fas receptor \\
\hline $\begin{array}{l}\text { Chitosan nanoparticles loaded with } \\
5 \text {-aminolaevulinic acid }\end{array}$ & Folic acid & $\begin{array}{l}\text { HT2 } 29 \text { colorectal cancer cell lines overexpressing } \\
\text { folate }\end{array}$ \\
\hline HPMA-copolymer-doxorubicin conjugates & Peptide GE11 & A431, HT29 and SW480 cell lines \\
\hline Mesoporous silica nanoparticle & Coated with poly-(L-lysine) and hyaluronic & HCT-116 cancer cells \\
\hline
\end{tabular}

PEG: polyethylene glycol; HPMA: hydroxypropyl methacrylate

types of nanoparticles. RES effect refers to the quick absorption of nanoparticles by macrophages which usually results in clearing nanoparticles from the circulation in vivo ${ }^{[51-53]}$. Specific types of nanoparticle coating may prevent and minimise the RES effect. Nanoparticles with surfactants or covalent linkage of polyoxyethylene have shown to effectively minimise the RES effect ${ }^{[54]}$. The size and shape of nanoparticles are the other two main factors that affect the delivery of conventional therapeutics to solid tumours. Nanoparticles larger than $500 \mathrm{~nm}$ are shown to be rapidly removed from the circulation in vivo ${ }^{[4,55]}$. In addition, targeted nanoparticles as a drug delivery system based on monoclonal antibodies are currently one of the main approaches for CRC therapy under preclinical development ${ }^{[5,57]}$. A list of these nanoplatforms is presented in Table 1.

\section{LIPOSOMES-BASED NANOPARTICLES}

The first therapeutic nano-platform applied in medicine was introduced by Bangham et al. ${ }^{[63]}$ in 1961 . This nano-platform was based on liposomes which were the first drug-delivery system approved by FDA for clinical practice. Liposome-based nanoparticles are one of the commonly used nanoparticles for delivering small peptides, nucleic acids, and proteins in nano-platform drug delivery ${ }^{[64-66]}$. Nanoliposomes are nontoxic, spherical nano-carriers containing an aqueous core with phospholipid bilayer ${ }^{[67,68]}$. Nanoliposomes are considered as one of the most effective drug delivery systems at a cellular level. This is mainly due to their size, ability to incorporate various substances and slow-releasing and targeting characteristics which also results in decreasing side effects ${ }^{[69,70]}$. There are three main types of nanoliposomes: (1) stealth liposomes or long-circulating liposomes, which have a modified phospholipid bilayer structure and added gangliosides or a polyethylene glycol (PEG) to assist avoiding blood plasma opsonins proteins binding to the liposome surface and minimise the RES effect; (2) active nanoliposomes: this type of nanoparticle targets receptors, hormones, peptides and antibodies; and (3) sensitive nanoliposomes: they are special active nanoliposomes with unique properties such as $\mathrm{pH}$-sensitive, thermo-sensitive and magnetic ${ }^{[21,70,71]}$. Doxorubicin (Doxil ${ }^{\circ}$--liposome is an example of FDA approved nanoliposome for chemotherapy for $\mathrm{CRC}^{[72]}$. Doxil is approximately $100 \mathrm{~nm}$ and although it has much less gastrointestinal and cardiac toxicity, it causes other side effects such as redness and peeling of the $\operatorname{skin}^{[73]}$. Marqibo ${ }^{\circ}$ is another recent nanoliposomal drug approved by $\mathrm{FDA}^{[74-76]}$. Marqibo is approximately $100 \mathrm{~nm}$ and it is a cell cycle-dependent anticancer drug. Thermo-sensitive liposome doxorubicin $\left(\right.$ Thermodox $\left.^{\otimes}\right)$ is another promising nanoliposomal drug for colorectal liver metastases in combination with radiofrequency ablation ${ }^{[77]}$. Thermodox ${ }^{\circledR}$ is a nanoliposomal with doxorubicin formulation which releases the drug upon a mild hyperthermic trigger ${ }^{[77]}$. Thermodox can deliver 25 fold more doxorubicin into tumours than IV doxorubicin does ${ }^{[77]}$.

\section{CORE-SHELL NANOPARTICLES}

There has been an increasing interest in developing and synthesizing core-shell nanoparticles ${ }^{[7,79]}$. The core-shell nanoparticles are composed of two or more materials which can be synthesised with different 


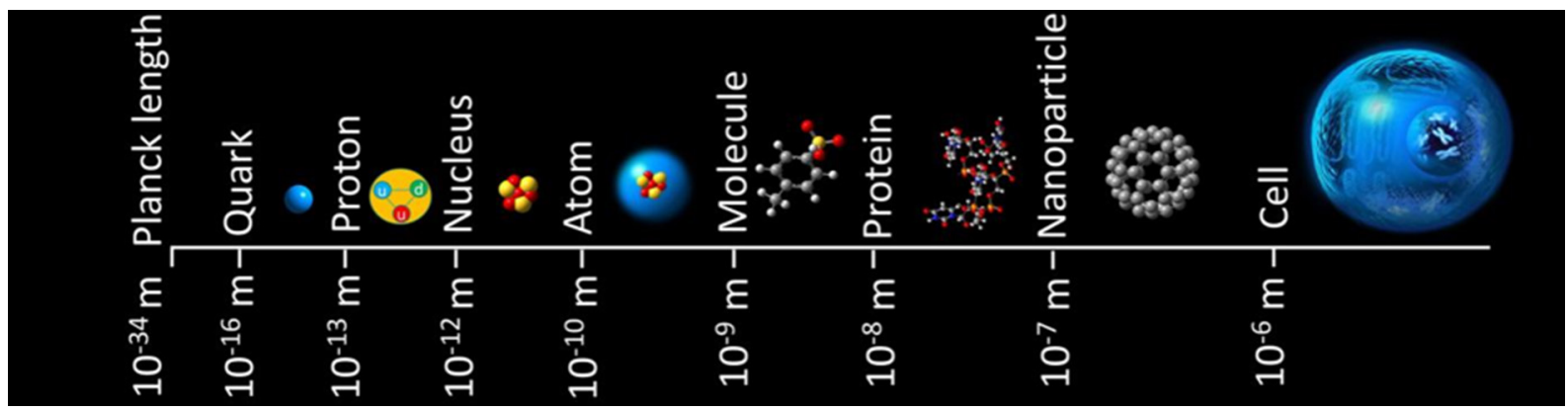

Figure 1. Illustration of relative sizes of objects

combinations of inorganic and organic materials ${ }^{[80]}$. To enable efficient surface modification, increasing the functionality and stability, the core nanoparticles is coated. The core-shell has different applications in the medical field such as controlled drug delivery, multimodal-imaging, cell labelling and nuclear medicine therapy ${ }^{[81,82]}$. Superparamagnetic iron oxide nanoparticles (SPIONs) are one of the most common core-shell nanoparticles that are used in medical imaging and therapy ${ }^{[33-93]}$.

\section{SPIONS}

SPIONs are nanoparticles that have become the focus of nanomedicine research since $1980^{[94]}$, and have evolved to include SPIONs with a biocompatible polymer coating and core surface modification specifically for nanomedicine and nuclear medicine applications. The key features of SPIONs include exhibiting magnetisation only in an applied magnetic field and the ability to load drugs and medical radioisotopes (due to their highly active surface). Over the past few decades, further developments in radiochemistry and radiation sciences have led to applying the field of nanomedicine to nuclear medicine for enabling multimodal medical imaging (radiolabelled nanoparticles with imaging isotopes) and radionuclide therapy (radiolabelled nanoparticles with therapeutic isotopes) of different types of cancer. This has significantly improved cancer diagnosis and therapy ${ }^{[95]}$. Currently nanoparticle-based magnetic resonance imaging (MRI) is utilised in cancer medicine for enhancing the MR image contrast. There are key advantages of SPION drug delivery including longer circulation half-lives, improved pharmacokinetics, capability to carrying a large amount of drugs, reduction in side effects and targeting the drug to a specific location in the body ${ }^{[26,38]}$.

Additionally, the doped gold-SPIONs have been developed for targeted photothermal therapy for destruction of $\mathrm{CRC}^{[96]}$. The developed gold-SPIONs were also functionalised with a single chain antibody to enable active targeting of the A33 antigen, which is overexpressed in CRC cells. Results demonstrated that the internalisation of gold-SPIONs was five times faster for cells expressing the A33 antigen than cells not expressing the antigen. Furthermore, this study has shown that upon 6 min of laser radiation exposure (with an $800 \mathrm{~nm}$ laser at $5.1 \mathrm{~W} \cdot \mathrm{cm}^{-2}$ ), 53\% A33-expressing cells died whereas only 5\% of A33 non-expressing cells died. These results demonstrated an excellent selectivity for targeting and killing CRC.

Moreover, SPION-based MRI has emerged as a common approach in medical imaging specifically of lymph nodes in solid cancers, including $\mathrm{CRC}^{[97]}$. This caused by a preferential uptake of SPIONs in lymph node as well as the ability of SPIONs to produce high contrast between cancerous and healthy tissues ${ }^{[96]}$. Due to the physical and chemical properties (e.g., highly reactive surface and magnetisation) of SPIONs, they have attracted enormous attention in cancer diagnosis and therapy ${ }^{[83-93]}$. SPIONs in vivo can perform actively (targeting a tissue or an organ) or passively. Peptide or antibody labelled SPIONs act as an active carrier for targeting the organ or tissue of interest. However, passive SPIONs mainly rely on the polymer type and particle size to achieve accumulation at the target site. Hydrophilic SPIONs with dextran and 
A)

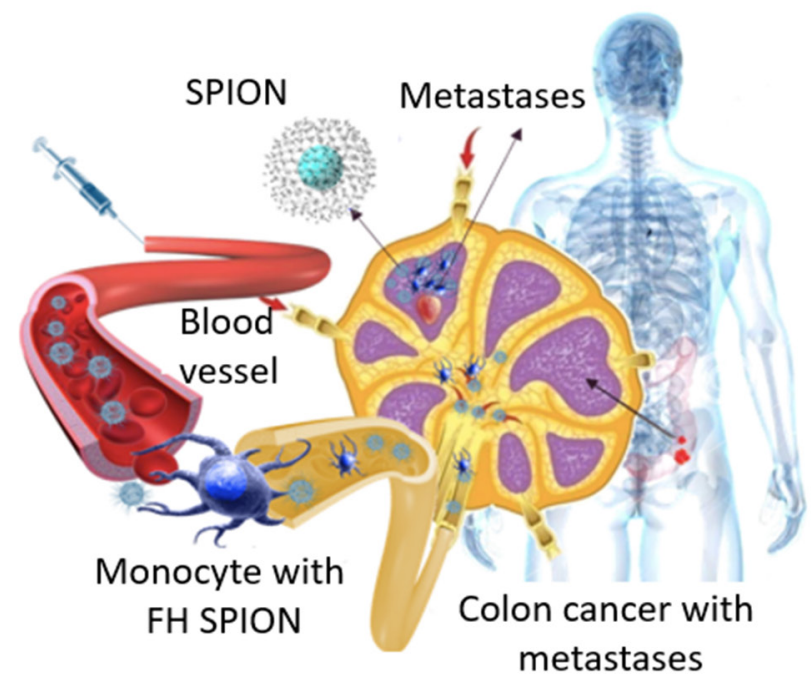

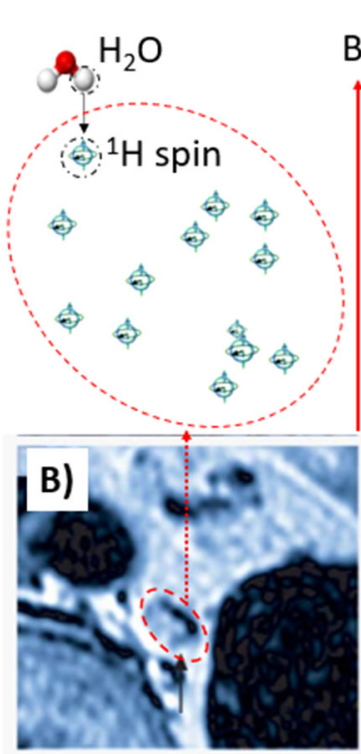

Conventional MRI
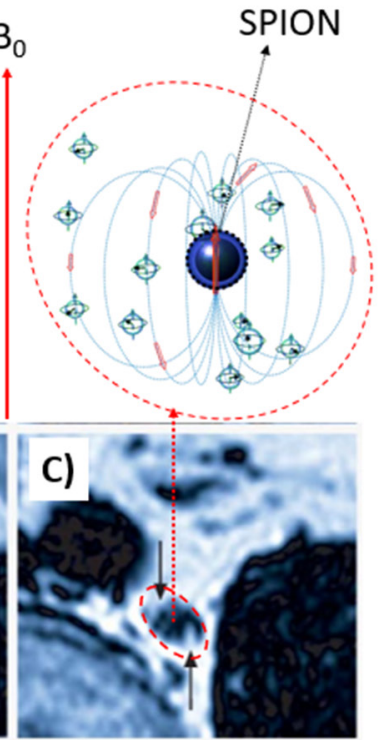

SPION-MRI

Figure 2. A: Following intravenous injection, SPIONs slowly extravasate from vascular space to interstitial space, from where they can be taken up by immune cells (monocytes/macrophages) and delivered via lymphatic vessels to lymph nodes. The SPIONs remain in normal nodal tissue and reduce MRI signal intensity, thereby enhancing contrast against any metastatic lesions in the node; B and C: demonstrating the mechanism of negative contrast agent, SPIONs in lymph node imaging; B: a conventional T2-weighted MR image of the lymph node showing the whole lymph node is associated with cancer metastases; C: the T2-weighted MR image of the lymph node with enhanced contrast produced by SPIONs showing only two small metastatic regions (e.g., hyper intense foci). The MR images in B and $\mathrm{C}$ were reproduced ${ }^{[96]}$. SPION: superparamagnetic iron oxide nanoparticle; MRI: magnetic resonance imaging

PEG surfaces are able to evade the RES as well as resisting the opsonisation (destruction by an immune cell) which leads to the increase of their biological half-life (circulation time) and the probability of targeting a specific cell ${ }^{[98-100]}$. Moreover, SPIONs with a size of less than $30 \mathrm{~nm}$ can also slowly extravasate from vascular space to interstitial space, from where they can be taken up by immune cells (monocytes/ macrophages) and delivered via lymphatic vessels to lymph nodes. These passive SPIONs can remain in normal nodal tissue and reduce MRI signal intensity, thereby enhancing contrast against any metastatic lesions in the node [Figure 2].

\section{CONCLUSION AND FUTURE DEVELOPMENT}

Nanoplatforms constitute valuable drug delivery systems that have been shown to serve the dual purpose of improving diagnostic accuracy and therapeutic effectiveness for CRCs. Cancer nanomedicine is a rapidly developing interdisciplinary research field that may have a transforming effect on diagnostic accuracy, toxicity and drug delivery specifically in rectal cancer. Finally, cancer nanomedicine for targeted drug delivery and enhanced imaging holds great promise and is moving from basic cell line research and subsequent animal studies work into the next stage of the translational pipeline: first-in-human trials.

\section{DECLARATIONS}

\section{Authors' contributions}

Preparing the article: Gholami YH

Revising it critically for important intellectual content: Engel A

\section{Availability of data and materials}

Not applicable. 


\section{Financial support and sponsorship}

None.

\section{Conflicts of interest}

All authors declared that there are no conflicts of interest.

\section{Ethical approval and consent to participate}

Not applicable.

\section{Consent for publication}

Not applicable.

\section{Copyright}

(c) The Author(s) 2018.

\section{REFERENCES}

1. Siegel RL, Miller KD, Jemal A. Cancer statistics, 2016. CA Cancer J Clin 2016;66:7-30.

2. Jemal A, Siegel R, Ward E, Murray T, Xu J, et al. Cancer statistics, 2007. CA Cancer J Clin 2007;57:43-66.

3. Murthy R, Kamat P, Nuñez R, Salem R. Radioembolization of yttrium-90 microspheres for hepatic malignancy. Semin Intervent Radiol 2008;25:48-57.

4. Abdalla EK, Vauthey JN, Ellis LM, Ellis V, Pollock R, et al. Recurrence and outcomes following hepatic resection, radiofrequency ablation, and combined resection/ablation for colorectal liver metastases. Ann Surg 2004;239:818-25.

5. Fong Y, Cohen AM, Fortner JG, Enker WE, Turnbull AD, et al. Liver resection for colorectal metastases. J Clin Oncol 1997;15:938-46.

6. Haggar FA, Boushey RP. Colorectal cancer epidemiology: incidence, mortality, survival, and risk factors. Clin Colon Rectal Surg 2009;22:191-7.

7. Weiss L. Fundamental aspects of metastasis. New York: American Elsevier Pub. Co; 1976.

8. Hellinger MD, Santiago CA. Reoperation for recurrent colorectal cancer. Clin Colon Rectal Surg 2006;19:228-36.

9. Janout V, Kollárová H. Epidemiology of colorectal cancer. Biomed Pap Med Fac Univ Palacky Olomouc Czech Repub 2001;145:5-10.

10. Steeg PS. Tumor metastasis: mechanistic insights and clinical challenges. Nat Med 2006;12:895-904.

11. Schroeder A, Heller DA, Winslow MM, Dahlman JE, Pratt GW, et al. Treating metastatic cancer with nanotechnology. Nat Rev Cancer 2011;12:39-50.

12. Wilczewska AZ, Niemirowicz K, Markiewicz KH, Car H. Nanoparticles as drug delivery systems. Pharmacol Rep 2012;64:1020-37.

13. Agnihotri SA, Aminabhavi TM. Novel interpenetrating network chitosan-poly(ethylene oxide-g-acrylamide) hydrogel microspheres for the controlled release of capecitabine. Int J Pharm 2006;324:103-15.

14. Sharma H. Role of external beam radiation therapy in management of hepatocellular carcinoma. J Clin Exp Hepatol 2014;4:S122-5.

15. dos Santos Giuberti C, de Oliveira Reis EC, Ribeiro Rocha TG, Leite EA, Lacerda RG, et al. Study of the pilot production process of long-circulating and $\mathrm{pH}$-sensitive liposomes containing cisplatin. J Liposome Res 2011;21:60-9.

16. Mijović J, Ristić S, Kenny J. Dynamics of six generations of PAMAM dendrimers as studied by dielectric relaxation spectroscopy. Macromolecules 2007;40:5212-21.

17. Park J, Fong PM, Lu J, Russell KS, Booth CJ, et al. PEGylated PLGA nanoparticles for the improved delivery of doxorubicin. Nanomedicine 2009;5:410-8.

18. Rejinold NS, Sreerekha PR, Chennazhi KP, Nair SV, Jayakumar R. Jayakumar. Biocompatible, biodegradable and thermo-sensitive chitosan-g-poly (N-isopropylacrylamide) nanocarrier for curcumin drug delivery. Int J Biol Macromol 2011;49:161-72.

19. Suri SS, Fenniri H, SinghB. Nanotechnology-based drug delivery systems. J Occup Med Toxicol 2007;2:16.

20. van den Hoven JM, Van Tomme SR, Metselaar JM, Nuijen B, Beijnen JH, et al. Liposomal drug formulations in the treatment of rheumatoid arthritis. Mol Pharm 2011;8:1002-15.

21. Akbarzadeh A, Samiei M, Davaran S. Magnetic nanoparticles: preparation, physical properties, and applications in biomedicine. Nanoscale Res Lett 2012;7:144.

22. Gatoo MA, Naseem S, Arfat MY, Dar AM, Qasim K, et al. Physicochemical properties of nanomaterials: implication in associated toxic manifestations. Biomed Res Int 2014;2014:498420.

23. Heiligtag FJ, Niederberger M. The fascinating world of nanoparticle research. Mater Today 2013;16:262-71.

24. Angioletti-Uberti S. Theory, simulations and the design of functionalized nanoparticles for biomedical applications: a soft matter perspective. Npj Comput Mater 2017;3:48.

25. Khan I, Saeed K, Khan I. Nanoparticles: properties, applications and toxicities. Available from: https://www.sciencedirect.com/science/ article/pii/S1878535217300990. [Last accessed on 14 Dec 2018]

26. Laroui H, Wilson DS, Dalmasso G, Salaita K, Murthy N, et al. Nanomedicine in GI. Am J Physiol Gastrointest Liver Physiol 2011;300:G371-83.

27. Laroui H, Dalmasso G, Nguyen HT, Yan Y, Sitaraman SV, et al. Drug-loaded nanoparticles targeted to the colon with polysaccharide hydrogel reduce colitis in a mouse model. Gastroenterology 2010;138:843-53.

28. Sajeesh S, Bouchemal K, Sharma CP, Vauthier C. Surface-functionalized polymethacrylic acid based hydrogel microparticles for oral 
drug delivery. Eur J Pharm Biopharm 2010;74:209-18.

29. Hu Z, Mawatari S, Shibata N, Takada K, Yoshikawa H, et al. Application of a biomagnetic measurement system (BMS) to the evaluation of gastrointestinal transit of intestinal pressure-controlled colon delivery capsules (PCDCs) in human subjects. Pharm Res 2000;17:160-7.

30. Veiseh O, Sun C, Fang C, Bhattarai N, Gunn J, et al. Specific targeting of brain tumors with an optical/magnetic resonance imaging nanoprobe across the blood-brain barrier. Cancer Res 2009;69:6200-7.

31. Fang C, Bhattarai N, Sun C, Zhang M. Functionalized nanoparticles with long-term stability in biological media. Small 2009;5:1637-41.

32. Yang L, Mao H, Cao Z, Wang YA, Peng X, et al. Molecular imaging of pancreatic cancer in an animal model using targeted multifunctional nanoparticles. Gastroenterology 2009;136:1514-25.

33. Kountouras J, Chatzopoulos D, Zavos C. Reactive oxygen metabolites and upper gastrointestinal diseases. Hepatogastroenterology 2001;48:743-51.

34. Mathew J, Joy J, George SC. Potential applications of nanotechnology in transportation: a review. Available from: https://ac.els-cdn. com/S1018364717310868/1-s2.0-S1018364717310868-main.pdf?.tid=33a4b98f-f2f2-4c7e-977d-ec3172ae82e7\&acdnat=1544752051 6aaa641ed07e4ffc5257e487bd9f5c12. [Last accessed on 14 Dec 2018]

35. Ealias AM, Saravanakumar MP. A review on the classification, characterisation, synthesis of nanoparticles and their application. IOP Conf Ser Mater Sci Eng 2017;263:032019.

36. Solvang S, Finholt P. Effect of tablet processing and formulation factors on dissolution rate of the active ingredient in human gastric juice. J Pharm Sci 1970;59:49-52.

37. Hörter D, Dressman JB. Influence of physicochemical properties on dissolution of drugs in the gastrointestinal tract. Adv Drug Deliv Rev 2001;46:75-87.

38. Batlle X, Labarta A. Finite-size effects in fine particles: magnetic and transport properties. Available from: http://iopscience.iop.org/artic le/10.1088/0022-3727/35/6/201/pdf. [Last accessed on 14 Dec 2018]

39. Roduner E. Size matters: why nanomaterials are different. Chem Soc Rev 2006;35:583-92.

40. Allen TM, Cullis PR. Drug delivery systems: entering the mainstream. Science 2004;303:1818-22.

41. Netti PA, Roberge S, Boucher Y, Baxter LT, Jain RK. Effect of transvascular fluid exchange on pressure-flow relationship in tumors: a proposed mechanism for tumor blood flow heterogeneity. Microvasc Res 1996;52:27-46.

42. Gullotti E, Yeo Y. Extracellularly activated nanocarriers: a new paradigm of tumor targeted drug delivery. Mol Pharm 2009;6:1041-51.

43. Matsumura Y, Maeda H. A new concept for macromolecular therapeutics in cancer chemotherapy: mechanism of tumoritropic accumulation of proteins and the antitumor agent smancs. Cancer Res 1986;46:6387-92.

44. Maeda H, Wu J, Sawa T, Matsumura Y, Hori K. Tumor vascular permeability and the EPR effect in macromolecular therapeutics: a review. J Control Release 2000;65:271-84.

45. Mishra S, Webster P, Davis ME. PEGylation significantly affects cellular uptake and intracellular trafficking of non-viral gene delivery particles. Eur J Cell Biol 2004;83:97-111.

46. Gryparis EC, Hatziapostolou M, Papadimitriou E, Avgoustakis K. Anticancer activity of cisplatin-loaded PLGA-mPEG nanoparticles on LNCaP prostate cancer cells. Eur J Pharm Biopharm 2007;67:1-8.

47. Romberg B, Hennink WE, Storm G. Sheddable coatings for long-circulating nanoparticles. Pharm Res 2008;25:55-71.

48. Hong RL, Huang CJ, Tseng YL, Pang VF, Chen ST, et al. Direct comparison of liposomal doxorubicin with or without polyethylene glycol coating in C-26 tumor-bearing mice: is surface coating with polyethylene glycol beneficial? Clin Cancer Res 1999;5:3645-52.

49. Kaasgaard T, Mouritsen OG, Jørgensen K. Screening effect of PEG on avidin binding to liposome surface receptors. Int J Pharm 2001;214:63-5.

50. Greish K. Enhanced permeability and retention of macromolecular drugs in solid tumors: a royal gate for targeted anticancer nanomedicines. J Drug Target 2007;15:457-64.

51. Torchilin VP. Targeted pharmaceutical nanocarriers for cancer therapy and imaging. AAPS J 2007;9:E128-47.

52. Owens DE 3rd, Peppas NA. Opsonization, biodistribution, and pharmacokinetics of polymeric nanoparticles. Int J Pharm 2006;307:93-102.

53. Howard MD, Jay M, Dziubla TD, Lu X. PEGylation of nanocarrier drug delivery systems: state of the art. J Biomed Nanotechnol 2008;4:133-48.

54. Kovacevic A, Savic S, Vuleta G, Müller RH, Keck CM. Polyhydroxy surfactants for the formulation of lipid nanoparticles (SLN and NLC): effects on size, physical stability and particle matrix structure. Int J Pharm 2011;406:163-72.

55. Cho M, Cho WS, Choi M, Kim SJ, Han BS, et al. The impact of size on tissue distribution and elimination by single intravenous injection of silica nanoparticles. Toxicol Lett 2009;189:177-83.

56. Brennan FR, Shaw L, Wing MG, Robinson C. Preclinical safety testing of biotechnology-derived pharmaceuticals: understanding the issues and addressing the challenges. Mol Biotechnol 2004;27:59-74.

57. Weinberg WC, Frazier-Jessen MR, Wu WJ, Weir A, Hartsough M, et al. Development and regulation of monoclonal antibody products: challenges and opportunities. Cancer Metastasis Rev 2005;24:569-84.

58. Vigor KL, Kyrtatos PG, Minogue S, Al-Jamal KT, Kogelberg H, et al. Nanoparticles functionalized with recombinant single chain Fv antibody fragments (scFv) for the magnetic resonance imaging of cancer cells. Biomaterials 2010;31:1307-15.

59. Tiernan JP, Ingram N, Marston G, Perry SL, Rushworth JV, et al. CEA-targeted nanoparticles allow specific in vivo fluorescent imaging of colorectal cancer models. Nanomedicine (Lond) 2015;10:1223-31.

60. Abdelghany SM, Schmid D, Deacon J, Jaworski J, Fay F, et al. Enhanced antitumor activity of the photosensitizer meso-Tetra(N-methyl4-pyridyl) porphine tetra tosylate through encapsulation in antibody-targeted chitosan/alginate nanoparticles. Biomacromolecules 2013;14:302-10

61. Fay F, McLaughlin KM, Small DM, Fennell DA, Johnston PG, et al. Conatumumab (AMG 655) coated nanoparticles for targeted proapoptotic drug delivery. Biomaterials 2011;32:8645-53.

62. da Paz MC, Santos Mde F, Santos CM, da Silva SW, de Souza LB, et al. Anti-CEA loaded maghemite nanoparticles as a theragnostic 
device for colorectal cancer. Int J Nanomedicine 2012;7:5271-82.

63. Bangham AD, Standish MM, Watkins JC. Diffusion of univalent ions across the lamellae of swollen phospholipids. J Mol Biol 1965;13:238-52.

64. Abreu AS, Castanheira EM, Queiroz MJ, Ferreira PM, Vale-Silva LA, et al. Nanoliposomes for encapsulation and delivery of the potential antitumoral methyl 6-methoxy-3-(4-methoxyphenyl)-1H-indole-2-carboxylate. Nanoscale Res Lett 2011;6:482.

65. Huynh NT, Passirani C, Saulnier P, Benoit JP. Lipid nanocapsules: a new platform for nanomedicine. Int J Pharm 2009;379:201-9.

66. Andresen TL, Jensen SS, Jørgensen K. Advanced strategies in liposomal cancer therapy: problems and prospects of active and tumor specific drug release. Prog Lipid Res 2005;44:68-97.

67. Silva R, Ferreira H, Cavaco-Paulo A. Sonoproduction of liposomes and protein particles as templates for delivery purposes. Biomacromolecules 2011;12:3353-68.

68. Patil YP, Jadhav S. Novel methods for liposome preparation. Chem Phys Lipids 2014;177:8-18.

69. Harashima H, Sakata K, Funato K, Kiwada H. Enhanced hepatic uptake of liposomes through complement activation depending on the size of liposomes. Pharm Res 1994;11:402-6.

70. Nag OK, Awasthi V. Surface engineering of liposomes for stealth behavior. Pharmaceutics 2013;5:542-69.

71. Noble GT, Stefanick JF, Ashley JD, Kiziltepe T, Bilgicer B. Ligand-targeted liposome design: challenges and fundamental considerations. Trends Biotechnol 2014;32:32-45.

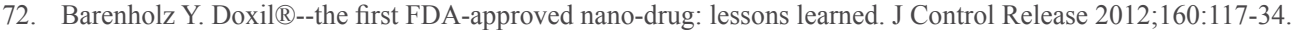

73. Rivera E. Liposomal anthracyclines in metastatic breast cancer: clinical update. Oncologist 2003;8 Suppl 2:3-9.

74. Allen TM, Cullis PR. Liposomal drug delivery systems: from concept to clinical applications. Adv Drug Deliv Rev 2013;65:36-48

75. Lam R, Ho D. Nanodiamonds as vehicles for systemic and localized drug delivery. Expert Opin Drug Deliv 2009;6:883-95.

76. Lammers T, Hennink WE, Storm G. Tumour-targeted nanomedicines: principles and practice. Br J Cancer 2008;99:392-7.

77. Stang J, Haynes M, Carson P, Moghaddam M. A preclinical system prototype for focused microwave thermal therapy of the breast. IEEE Trans Biomed Eng 2012;59:2431-8.

78. Hirsch LR, Stafford RJ, Bankson JA, Sershen SR, Rivera B, et al. Nanoshell-mediated near-infrared thermal therapy of tumors under magnetic resonance guidance. Proc Natl Acad Sci U S A 2003;100:13549-54.

79. Loo C, Lowery A, Halas N, West J, Drezek R. Immunotargeted nanoshells for integrated cancer imaging and therapy. Nano Lett 2005;5:709-11.

80. Damascelli B, Cantù G, Mattavelli F, Tamplenizza P, Bidoli P, et al. Intraarterial chemotherapy with polyoxyethylated castor oil free paclitaxel, incorporated in albumin nanoparticles (ABI-007): phase I study of patients with squamous cell carcinoma of the head and neck and anal canal: preliminary evidence of clinical activity. Cancer 2001;92:2592-602.

81. Zhang L, Chen H, Wang L, Liu T, Yeh J, et al. Delivery of therapeutic radioisotopes using nanoparticle platforms: potential benefit in systemic radiation therapy. Nanotechnol Sci Appl 2010;3:159-70.

82. Bai Y, Teng B, Chen S, Chang Y, Li Z. Preparation of magnetite nanoparticles coated with an amphiphilic block copolymer: a potential drug carrier with a core-shell-corona structure for hydrophobic drug delivery. Macromol Rapid Commun 2006;27:2107-112.

83. Bajpai AK, Gupta R. Magnetically mediated release of ciprofloxacin from polyvinyl alcohol based superparamagnetic nanocomposites. J Mater Sci Mater Med 2011;22:357-69.

84. Arias JL, López-Viota M, Delgado AV, Ruiz MA. Iron/ethylcellulose (core/shell) nanoplatform loaded with 5-fluorouracil for cancer targeting. Colloids Surf B Biointerfaces 2010;77:111-6.

85. Gaihre B, Khil MS, Lee DR, Kim HY. Gelatin-coated magnetic iron oxide nanoparticles as carrier system: drug loading and in vitro drug release study. Int J Pharm 2009;365:180-9.

86. Hua MY, Liu HL, Yang HW, Chen PY, Tsai RY, et al. The effectiveness of a magnetic nanoparticle-based delivery system for BCNU in the treatment of gliomas. Biomaterials 2011;32:516-27.

87. Hua MY, Yang HW, Chuang CK, Tsai RY, Chen WJ, et al. Magnetic-nanoparticle-modified paclitaxel for targeted therapy for prostate cancer. Biomaterials 2010;31:7355-63.

88. Jingting C, Huining L, Yi Z. Preparation and characterization of magnetic nanoparticles containing $\mathrm{Fe}(3) \mathrm{O}(4)$-dextran-anti- $\beta$-human chorionic gonadotropin, a new generation choriocarcinoma-specific gene vector. Int J Nanomedicine 2011;6:285-94.

89. Kempe M, Kempe H, Snowball I, Wallén R, Arza CR, et al. The use of magnetite nanoparticles for implant-assisted magnetic drug targeting in thrombolytic therapy. Biomaterials 2010;31:9499-510.

90. Losic D, Yu Y, Aw MS, Simovic S, Thierry B, et al. Surface functionalisation of diatoms with dopamine modified iron-oxide nanoparticles: toward magnetically guided drug microcarriers with biologically derived morphologies. Chem Commun (Camb) 2010;46:6323-5.

91. Tong Q, Li H, Li W, Chen H, Shu X, et al. In vitro and in vivo anti-tumor effects of gemcitabine loaded with a new drug delivery system. J Nanosci Nanotechnol 2011;11:3651-8.

92. Wu W, Chen B, Cheng J, Wang J, Xu W, et al. Biocompatibility of Fe3O4/DNR magnetic nanoparticles in the treatment of hematologic malignancies. Int J Nanomedicine 2010;5:1079-84.

93. Yang J, Park SB, Yoon HG, Huh YM, Haam S. Preparation of poly epsilon-caprolactone nanoparticles containing magnetite for magnetic drug carrier. Int J Pharm 2006;324:185-90.

94. Wáng YX, Idée JM. Idée. A comprehensive literatures update of clinical researches of superparamagnetic resonance iron oxide nanoparticles for magnetic resonance imaging. Quant Imaging Med Surg 2017;7:88-122.

95. Ting G, Chang CH, Wang HE, Lee TW. Nanotargeted radionuclides for cancer nuclear imaging and internal radiotherapy. J Biomed Biotechnol 2010; doi: 10.1155/2010/953537.

96. Revia RA, Zhang M. Magnetite nanoparticles for cancer diagnosis, treatment, and treatment monitoring: recent advances. Mater Today (Kidlington) 2016;19:157-68. 
97. Harisinghani MG, Barentsz J, Hahn PF, Deserno WM, Tabatabaei S, et al. Noninvasive detection of clinically occult lymph-node metastases in prostate cancer. N Engl J Med 2003;348:2491-9.

98. Tassa C, Shaw SY, Weissleder R. Dextran-coated iron oxide nanoparticles: a versatile platform for targeted molecular imaging, molecular diagnostics, and therapy. Acc Chem Res 2011;44:842-52.

99. Jedlovszky-Hajdú A, Bombelli FB, Monopoli MP, Tombácz E, Dawson KA. Surface coatings shape the protein corona of SPIONs with relevance to their application in vivo. Langmuir 2012;28:14983-91.

100. Weissleder R, Nahrendorf M, Pittet MJ. Imaging macrophages with nanoparticles. Nat Mater 2014;13:125-38. 